\title{
Hensen's node, but not other biological signallers, can induce supernumerary digits in the developing chick limb bud
}

\author{
Kate Mary Stocker ${ }^{1,2}$ and Bruce Martin Carlson ${ }^{1,3}$ \\ ${ }^{1}$ Department of Biology, University of Michigan, Ann Arbor, MI, 48109 \\ 2 Department of Cell Biology and Anatomy, Oregon Health Sciences University, Portland, OR 97201 \\ ${ }^{3}$ Department of Anatomy and Cell Biology, University of Michigan, Ann Arbor, MI 48109, USA
}

Received August 14, 1989/Accepted in revised form November 29, 1989

\begin{abstract}
Summary. The purpose of this study was to determine whether the organizer regions of early avian and amphibian embryos could induce supernumerary (SN) wing structures to develop when they were grafted to a slit in the anterior side of stage 19-23 chick wing buds. Supernumerary digits developed in $43 \%$ of the wings that received anterior grafts of Hensen's node from stage 4-6 quail or chick embryos; in addition, $16 \%$ of the wings had rods of SN cartilage, but not recognizable SN digits. The grafted quail tissue did not contribute to the SN structures. When tissue anterior or lateral to Hensen's node or lateral pieces of the area pellucida caudal to Hensen's node were grafted to anterior slits, the wings usually developed normally. No SN structures developed when Hensen's nodes were grafted to posterior slits in chick wing buds. Wings developed normally when pieces of the dorsal lip of the blastopore from stage 10-11.5 frog (Xenopus laevis and Rana pipiens) embryos were grafted to anterior slits. No SN digits developed when other tissues that have limb-inducing activity in adult urodele amphibians [chick otic vesicle, frog (Rana pipiens) lung and kidney] or that can act as heteroinductors in neural induction (rat kidney, lung, submaxillary gland and urinary bladder; mouse liver and submaxillary gland) were grafted to anterior slits in chick wing buds. SN digits also failed to develop following preaxial grafts of chick optic vesicles. These results suggest that although the anteroposterior polarity of the chick wing bud can be influenced by factors other than the ZPA (e.g., Hensen's node, retinoids), the wing is not so labile that it can respond to a wide variety of inductively-active tissues.
\end{abstract}

Key words: Chick embryo - Extremities (limbs) - Morphogenesis

Offprint requests to: K.M. Stocker, Department of Cell Biology and Anatomy, L215, Oregon Health Sciences University, 3181 S.W. Sam Jackson Park Road Portland, Oregon 97201, USA

\section{Introduction}

In 1968, Saunders and Gasseling identified a region of tissue on the posterior side of the chick wing bud which, when grafted to the anterior side of a host wing bud, causes supernumerary (SN) digits to develop. The SN digits are arranged in mirror-image symmetry relative to the host digits, with the most posterior digit always forming adjacent to the grafted tissue (graft 432234, where the normal anterior-to-posterior pattern is digits 234). The region of grafted tissue was thus named the zone of polarizing activity (ZPA). Fallon and Crosby (1977) demonstrated that the limb buds of other amniotes (rodents, pigs, humans, turtles) have a ZPA that will stimulate SN wing digits to develop when it is grafted to the anterior side of a host chick wing.

Tickle et al. (1975) proposed that the ZPA is the source of a diffusible morphogen that forms a gradient across the anteroposterior axis of the wing bud. The morphogen concentration is postulated to be highest on the posterior side of the wing and lowest on the anterior side. The local morphogen concentration is thought to provide positional information to the cells, so that cells in the anterior side of the wing, for example, interpret the low morphogen concentration to form anterior structures. When a ZPA is grafted to the anterior side of the wing, the morphogen concentration in this region would rise to higher levels and the anterior cells would interpret this positional information to form posterior structures. Thus cells with anterior positional values can be respecified to acquire more posterior positional values; in addition, new cells are generated by cell division that is stimulated by the grafted ZPA.

Saunders (1977) reported that polarizing activity can be detected in various embryonic chick tissues other than the ZPA if these tissues are implanted directly under the apical ectodermal ridge (AER) on the anterior side of a host wing bud. He found polarizing activity in flank, 
mesonephros, tail bud mesoderm, and somites from the limb region. Saunders and Gasseling (1983) suggested that these non-limb tissues may provide " posterior positional information" for cells of the host limb bud.

Hornbruch and Wolpert (1986) demonstrated that Hensen's nodes from stage $4-9$ chick embryos can induce supernumerary digits to develop when grafted directly under the AER on the anterior side of host chick wing buds. However, the polarizing activity of the Hensen's node grafts was less than that of ZPA grafts: fewer wings developed SN digits and SN digit 4's (the most posterior digit) never developed.

Supernumerary digits also develop when a small bead that has been soaked in retinoic acid is implanted under the AER on the anterior side of a wing bud (Tickle et al. 1985). Skeletal development is normal if the bead is grafted to the posterior side of the wing. Exogenous retinoic acid has also been shown to affect pattern formation in the proximodistal and anteroposterior axes of regenerating amphibian limbs (Maden 1982, 1985; Kim and Stocum 1986a, b). In both amphibians and chicks, retinoic acid is postulated to alter the positional values of responding cells.

More recently, endogenous retinoic acid and retinoic acid-binding proteins have been demonstrated in amphibian (Maden 1985) and chick (Thaller and Eichele 1987; Maden et al. 1988) limb buds. In stage 21 chick embryos, retinoic acid forms a concentration gradient across the limb bud, with the high point in the posterior region that also contains the ZPA. Thaller and Eichele (1987) suggest that the concentration gradient of endogenous retinoic acid could define cell position and hence specify the anteroposterior pattern of the developing limb.

The experiments described here were designed to answer the following question: Can the organizer regions of early avian and amphibian embryos (Hensen's node and the dorsal lip of the blastopore, respectively) induce $\mathrm{SN}$ wing structures to develop when they are grafted to the anterior side of a host chick wing bud? This study was in progress when Hornbruch and Wolpert's (1986) paper on the polarizing activity of chick Hensen's node grafts was published, but differs from that study in two major respects. First, we used grafts of Hensen's nodes from quail embryos to chick hosts so that we could determine whether the graft itself contributed to the SN structures. Second, we determined the specificity of the $\mathrm{SN}$ response by testing the polarizing activity of various other tissues, including a) tissues that induce SN limbs to develop when implanted subcutaneously in newt forelimbs [frog lung and kidney (Carlson 1967, 1971); newt otic vesicle (Balinsky 1925)] and b) tissues that act as heteroinductors in neural induction in amphibians [rat kidney, lung, submaxillary gland, urinary bladder; mouse liver and submaxillary gland (Saxen and Toivonen 1962)]. We used chick instead of newt otic vesicles and also tested the ability of the chick optic cup, which can induce a lens to form in overlying ectoderm, to induce SN digits when it is grafted to the anterior side of a chick wing bud.

\section{Materials and methods}

\section{Grafting operations}

Stage 19-23 (Hamburger and Hamilton 1951) chicken embryos (Gallus domesticus) were used as hosts. The fertilized eggs were obtained from Michigan State University Poultry Farm, Lansing, MI, USA, and were incubated in a forced-air incubator at $37.5^{\circ} \mathrm{C}$. On the day before the operation, the eggs were candled and $2 \mathrm{ml}$ of albumen was withdrawn from each egg. On the following day, a window was cut in the shell above the embryo and one or two drops of an antibiotic solution (200 IU penicillin $/ \mathrm{ml}$ and $0.2 \mathrm{mg}$ streptomycin $/ \mathrm{ml}$ in Hanks' buffered salt solution) were added to each egg. The windows were then sealed with tape (Blenderm, 3M Co.).

Before each operation, the membranes overlying the embryo were cut with iridectomy scissors. The graft tissue (Hensen's node or other tissue) was placed into a slit made in the anterior side of the wing bud (approximately at the level of somites 15-16) of the host embryo. An additional one or two drops of antibiotic solution were added to the egg and the wing was traced with a camera lucida to record the position of the graft. The window was sealed with tape and the egg was returned to the incubator for 6-7 days.

\section{Graft tissues}

Organizer grafts. Japanese quail (Coturnix coturnix japonica) and chicken (Gallus domesticus) embryos of stages 4-6 were used as sources of Hensen's node grafts. Hensen's nodes were cut from the blastoderms and placed in phosphate-buffered saline (PBS, Gib$\mathrm{co}$ ). The grafts were used whole or were cut in half (along the anteroposterior axis of the primitive streak) if they were large.

Grafts were also cut from various positions around Hensen's node to determine the distribution of the polarizing activity. These positions included tissue immediately anterior to Hensen's node (notochord), immediately lateral to Hensen's node, and area pellucida caudal to Hensen's node and lateral to the primitive streak (Fig. 1)

Frog embryos (Rana pipiens and Xenopus laevis) of stages 10 11.5 (Shumway 1940; Nieuwkoop and Faber 1956, respectively) were used to obtain grafts of the dorsal lip of the blastopore. Fertilized Xenopus laevis (Carolina Biological Supply Co., Burlington, NC, USA) and Rana pipiens (Wisconsin strain, Kons Scientific Co. Inc., Germantown, WI, USA) eggs were incubated in well water at $17-21^{\circ} \mathrm{C}$ until they were used. They were then placed in $20 \%$ Steinberg's solution, the jelly coats and vitelline membranes were removed, and the dorsal lip of the blastopore was dissected out.

Grafts of limb-inducing tissues. The lungs and kidneys were removed from adult male and female Rana pipiens (Wisconsin strain, Kons Scientific Co. Inc., Germantown, WI, USA) that had been killed by cervical dislocation. The tissues were placed in $0.6 \% \mathrm{NaCl}$. All regions of the kidney, and bronchi and parenchyma of the lungs were used for grafts.

We used otic vesicles from chicken embryos (Hamburger and Hamilton stages 17-19) rather than from newts (Balinsky 1925). The grafts were placed in PBS until they were used.

Grafts of heteroinductors. Kidney, submaxillary gland, and urinary bladder grafts were obtained from 2-2.5 month-old male rats (F455). A female rat (F455, 2 months old) was used as a source of lung tissue. The rats were killed by cervical dislocation and the tissues were dissected out and placed in $0.9 \% \mathrm{NaCl}$. The cortex of the kidney, all regions of the lung, parenchyma and some duct and vascular tissue of the submaxillary gland, and all regions of the urinary bladder, with the epithelium, were used. 


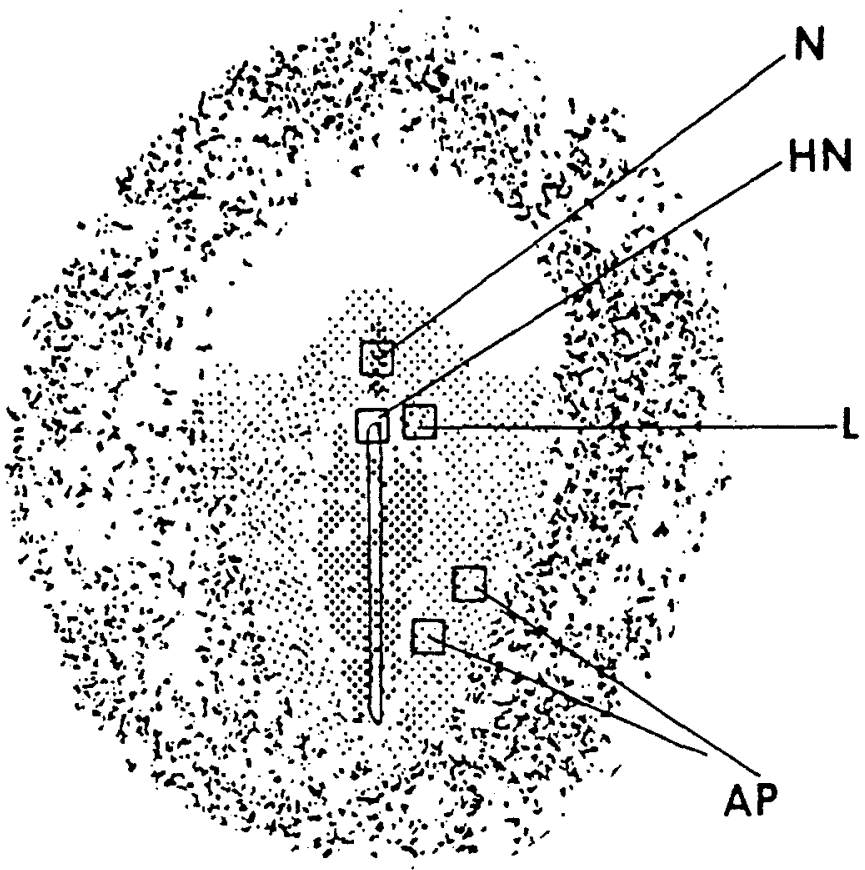

Fig. 1. Diagram of stage 5 chick embryo (dorsal view). The regions of tissue used for grafts are outlined and labeled: $H N=$ Hensen's node; $N=$ developing notochord anterior to Hensen's node; $L=$ tissue lateral to Hensen's node; $A P=$ area pellucida caudal to Hensen's node and lateral to the primitive streak

Grafts of liver and submaxillary gland were obtained from male C57 mice (2.5 and 1.5 months old, respectively) that had been killed by cervical dislocation. The tissues were placed in $0.9 \%$ $\mathrm{NaCl}$ and all regions of the liver and submaxillary gland were used for grafts.

Optic cup grafts. The optic cups (plus lens placode in embryos older than stage 13) were dissected from stage 13-17 chicken embryos. The lens placode was usually left on the optic cup, which was then bisected to create two grafts.
Preparation of grafts. All graft tissues were trimmed to approximately $100 \mu \mathrm{m}^{3}$ and were stained lightly with Nile blue sulfate before they were implanted.

\section{Controls}

Standard grafts of stage 4-6 chick and quail Hensen's nodes [and tissue anterior (notochord) and lateral to Hensen's node] were implanted in slits made in the posterior side (in the region of the prospective elbow) of wings of stage 19-23 host chick embryos. In all other respects the operations were the same as described above.

\section{Histological procedures}

The operated embryos were killed by decapitation 6-7 days after the operation and the wings were fixed in alcohol-formaldehydeacetic acid fixative (Carlson et al. 1986). They were stained using a combined Feulgen and Victoria blue B procedure (Carlson et al. 1986). This was particularly useful for analyzing the results of quail grafts to chick embryos: the Victoria blue B dye stains the cartilage so that the skeletal pattern can be examined and photographed in whole mount preparations, and the quail cells can be identified in serial sections on the basis of the large, densely-staining (Feulgen) clumps of heterochromatin in their nuclei (LeDouarin 1973). This allowed us to determine the contribution (if any) of the grafted quail cells to the SN structures.

The whole mount preparations were photographed with a Nikon Macrophot camera and Polaroid Type $55 \mathrm{film}$. They were then embedded in paraffin and $7 \mu \mathrm{m}$ sagittal sections were cut. The sections were mounted on glass slides and counterstained with fast green.

\section{Results}

\section{Organizer grafts}

Supernumerary digits developed in 43\% (26/61) of the wings in which chick or quail Hensen's nodes were grafted to anterior slits (Fig. 2a-c, Table 1). Supernu-

Table 1. The formation of supernumerary structures after grafts of chick or quail Hensen's nodes, or the dorsal lip of the blastopore from frog embryos, into anterior slits in chick wing buds

\begin{tabular}{|c|c|c|c|c|c|}
\hline $\begin{array}{l}\text { Tissue grafted } \\
\text { to anterior slit }\end{array}$ & $\begin{array}{l}\text { Normal } \\
\text { wings }\end{array}$ & SN digits ${ }^{a}$ & $\begin{array}{l}\text { SN rods } \\
\text { or nodules }\end{array}$ & $\begin{array}{l}\text { "Other } \\
\text { non-SN"b }\end{array}$ & $\begin{array}{l}\text { Other } \\
\text { anomaly }\end{array}$ \\
\hline $\begin{array}{l}\text { Hensen's node } \\
\text { (stage 4-6 quail embryos) } \\
n=56\end{array}$ & $\begin{array}{l}20 \\
(35 \%)\end{array}$ & $\begin{array}{l}23 \\
(42 \%)\end{array}$ & $\begin{array}{l}9 \\
(16 \%)\end{array}$ & $\begin{array}{l}4 \\
(7 \%)\end{array}$ & 8 \\
\hline $\begin{array}{l}\text { Hensen's node } \\
\text { (stage 4-6 chick embryos) } \\
n=5\end{array}$ & $\begin{array}{c}1 \\
(20 \%)\end{array}$ & $\begin{array}{l}3 \\
(60 \%)\end{array}$ & $\begin{array}{l}1 \\
(20 \%)\end{array}$ & - & - \\
\hline $\begin{array}{l}\text { Dorsal lip of blastopore } \\
\text { (stage } 10-11.5 \text { Xenopus laevis } \\
\text { or Rana pipiens) } \\
n=30\end{array}$ & $\begin{array}{l}28 \\
(93 \%)\end{array}$ & - & - & $\begin{array}{l}2 \\
(7 \%)\end{array}$ & 4 \\
\hline
\end{tabular}

a $50 \%(18 / 36)$ of the wings with $\mathrm{SN}$ digits, rods; or nodules had SN structures proximal to the graft, usually in addition to SN structures that developed distal to the graft

b "Other non-SN" refers to wings with slight abnormalities (e.g., reduction of the radius), but no SN structures

c Other anomaly refers to wings with grossly abnormal skeletal patterns (e.g., bent humerus, missing radius or ulna). These wings were not included in the calculations of the percentage of SN structures 


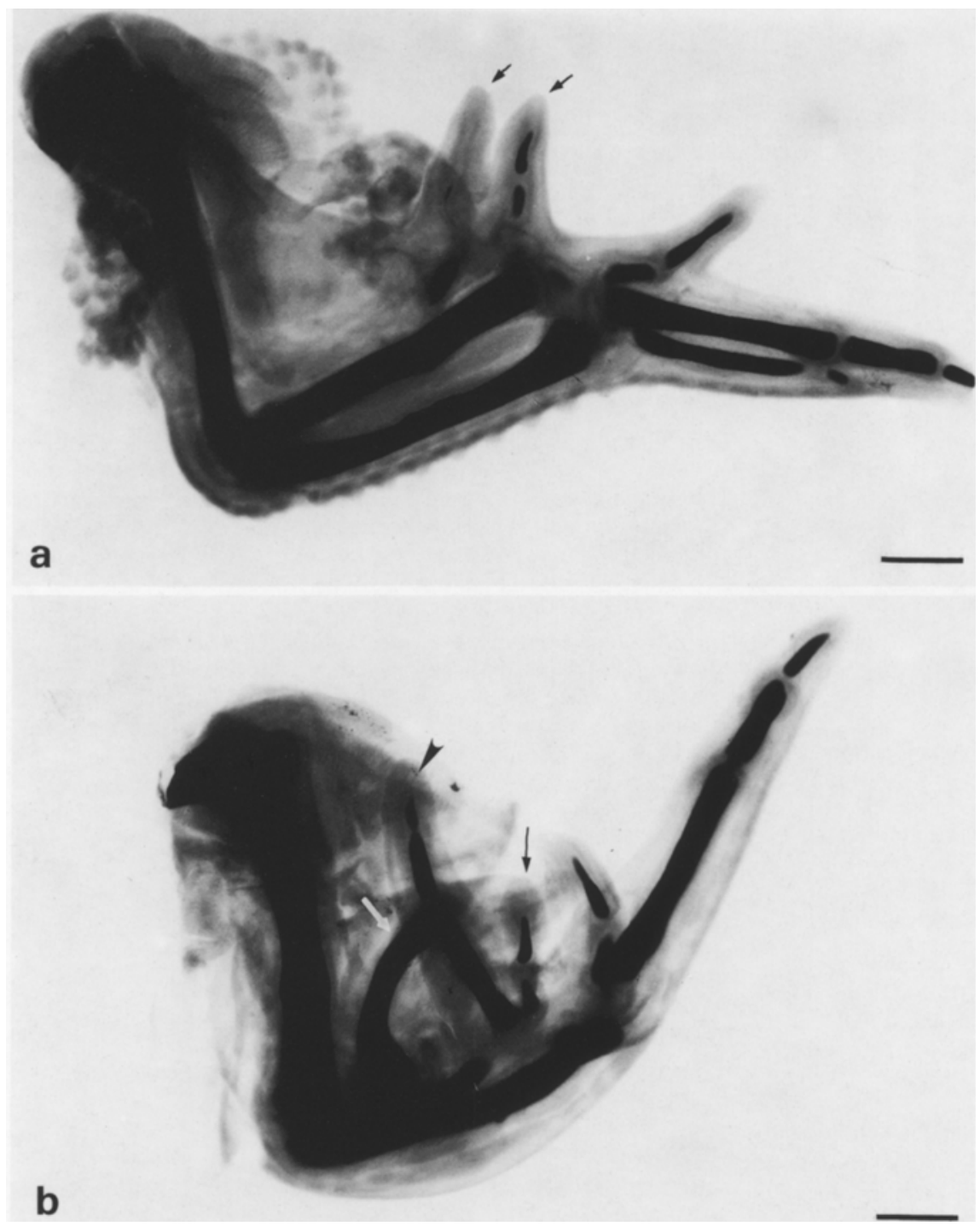

Fig. 2a-d. Examples of chick wings with supernumerary ( $\mathrm{SN}$ ) structures that were induced by preaxial grafts of Hensen's nodes from stage 4-6 chick or quail embryos. Wings in this and subsequent figures were stained by combined FeulgenVictoria blue B technique (Scale bar, $1 \mathrm{~mm}$ ). a Supernumerary digits (arrows). Proximal SN digit has only a slip of cartilage; distal SN digit was identified by morphological criteria as a digit 2. Graft from stage 4 quail embryo; host was stage 21 chick embryo. b Supernumerary digits (black arrow and arrowhead). Proximal SN digit (arrowhead) was identified by morphological criteria as a digit 3; distal SN digit (arrow) was identified as a digit 2 .

Unidentifiable rod of SN cartilage is marked by white arrow. Radius of limb is short; normal digit 4 is hidden behind digit 3 . Graft from stage 4 quail embryo; host was stage $20+$ chick embryo. c Supernumerary digit 2 (arrow) and rod of SN cartilage (duplicated radius?) with faintly stained hypomorphic digit on its distal end (arrowhead). Base of normal radius and rod are fused. Graft from stage 4 chick embryo; host was stage 22 chick embryo. d Unidentifiable SN structures (arrow and arrowhead). Distal SN structure (arrow) is attached to middle of radius. Proximal SN structure (arrowhead) has a faint slip of cartilage. Normal digit 4 is partially hidden behind digit 3. Graft from stage 4 quail embryo; host was stage 21 chick embryo

merary rods of cartilage, but not recognizable digits, developed in 16\% (10/61) of the wings (Fig. 2d, Table 1), while most of the remaining wings were normal. Four wings were classified as "other non-SN" because although they did not have any SN structures, they had minor abnormalities, such as a short radius or the proximal end of the radius was missing. Eight wings were not included in the calculations because they had grossly abnormal skeletal patterns such as a bent humerus or missing radius or ulna.

In contrast to the results with avian Hensen's node grafts, no supernumerary digits, rods or nodules of cartilage developed in wings that had received grafts of amphibian "organizers". The majority of the operated wings were normal (Table 1).

The ability of the grafted quail or chick tissue to induce the formation of SN digits (or SN rods or nodules of cartilage) was restricted to the Hensen's node region at stages 4-6: no SN structures developed following grafts of tissue anterior, lateral, or caudal to Hensen's
Table 2. Responses of chick wing buds to anterior grafts of tissue surrounding Hensen's node from stage 4-6 quail embryos (see Fig. 1)

\begin{tabular}{lllll}
\hline $\begin{array}{l}\text { Tissue grafted } \\
\text { to anterior slit }\end{array}$ & $\begin{array}{l}\text { Normal } \\
\text { wings }\end{array}$ & $\begin{array}{l}\text { SN digits, "Other } \\
\text { rods, or } \\
\text { nodules }\end{array}$ & $\begin{array}{l}\text { Other } \\
\text { non-SN" }\end{array}$ \\
anomalyc
\end{tabular}

$b, c$ see footnotes to Table 1 


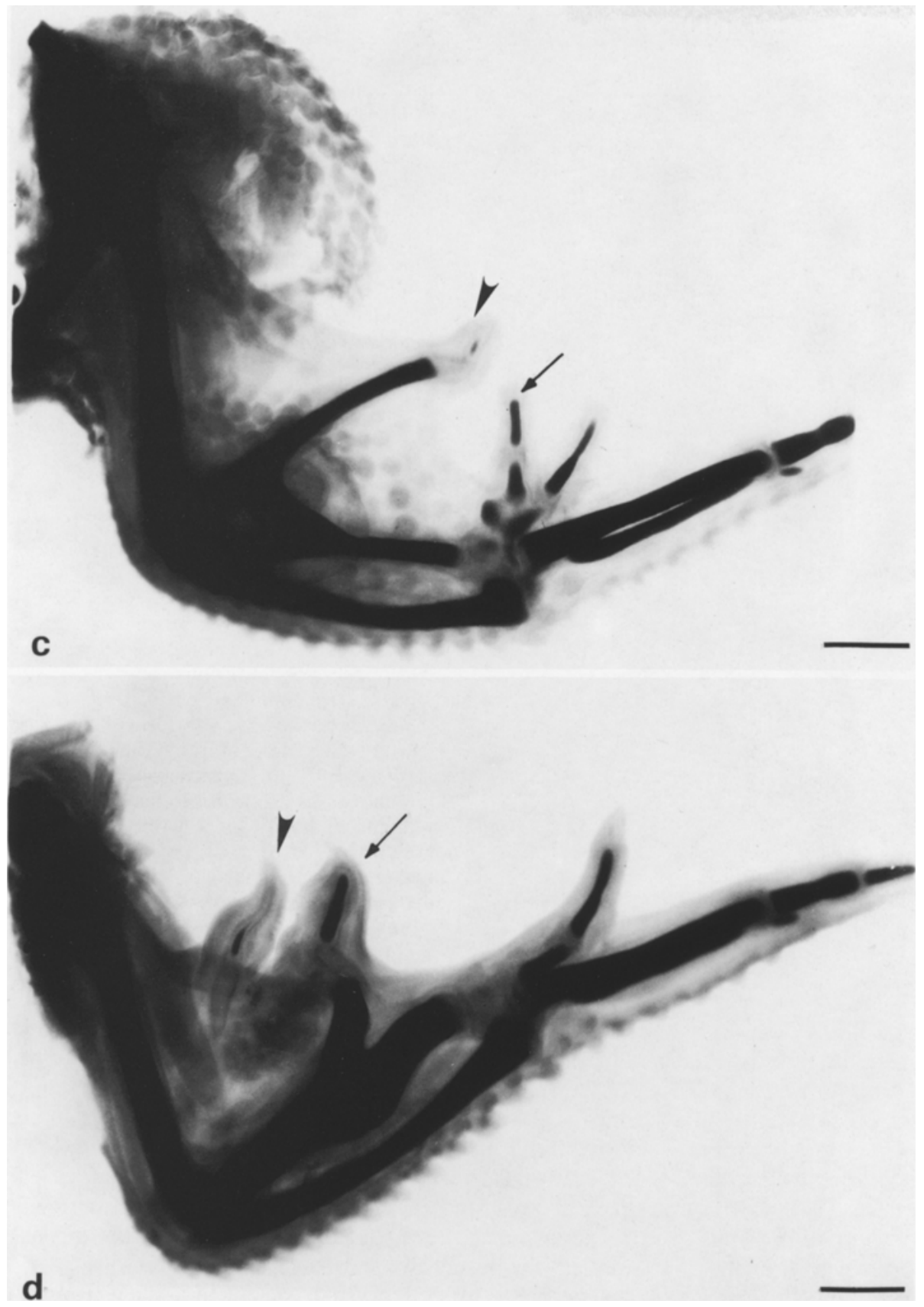

Fig. 2

node to the anterior side of host wing buds (Table 2). In each case, the majority of the wings had normal skeletal patterns and a few were classified as "other non-SN" or were grossly abnormal.

The patterns of SN digits that developed in wings with grafts of quail or chick Hensen's nodes were varied (Fig. 2, Table 3). The most common pattern was 2234 and SN digit 4's never developed. In many of the wings one or more SN digits could not be identified: $30 \%$ of the wings had a $? 2234$ pattern and in $17 \%$ of the wings the pattern was ?234, where ? represents an unidentifiable digit. A small number of wings had the patterns 3234, ?32234, ?334, ??2234.
Of the wings that developed with $\mathrm{SN}$ digits or SN rods or nodules of cartilage, $50 \%(18 / 36)$ had SN structures proximal to the graft, usually in addition to $\mathrm{SN}$ structures that developed distal to the graft (Fig. 3, Table 1). These proximal supernumerary structures were cartilage rods in $56 \%(10 / 18)$ of the cases and digits or other recognizable wing structures (radius or ulna) in the remaining cases $(8 / 18)$.

\section{Grafts of other tissues}

No SN digits developed in wings in which limb-inducing tissues had been grafted to an anterior slit (Table 4). 
Table 3. The patterns of supernumerary digits that developed after grafts of chick or quail Hensen's nodes to anterior slits in chick wing buds

\begin{tabular}{|c|c|c|c|c|c|c|c|}
\hline \multirow{2}{*}{$\begin{array}{l}\text { Tissue grafted } \\
\text { to anterior slit }\end{array}$} & \multicolumn{7}{|c|}{ Digital pattern } \\
\hline & 2234 & $? 2234^{\mathrm{a}}$ & $? 234^{\mathrm{a}}$ & 3234 & $? 32234^{\mathrm{a}}$ & $? 334^{\mathrm{a}}$ & $? ? 2234^{\mathrm{a}}$ \\
\hline $\begin{array}{l}\text { Quail Hensen's node } \\
n=23\end{array}$ & $\begin{array}{l}6 \\
(26 \%)\end{array}$ & $\begin{array}{l}7 \\
(31 \%)\end{array}$ & $\begin{array}{l}4 \\
(18 \%)\end{array}$ & $\begin{array}{l}3 \\
(13 \%)\end{array}$ & $\begin{array}{l}1 \\
(4 \%)\end{array}$ & $\begin{array}{l}1 \\
(4 \%)\end{array}$ & $\begin{array}{l}1 \\
(4 \%)\end{array}$ \\
\hline $\begin{array}{l}\text { Chick Hensen's node } \\
n=3\end{array}$ & $\begin{array}{l}2 \\
(67 \%)\end{array}$ & - & $\begin{array}{l}1 \\
(33 \%)\end{array}$ & - & - & - & - \\
\hline
\end{tabular}

a $?$ represents an unidentifiable digit

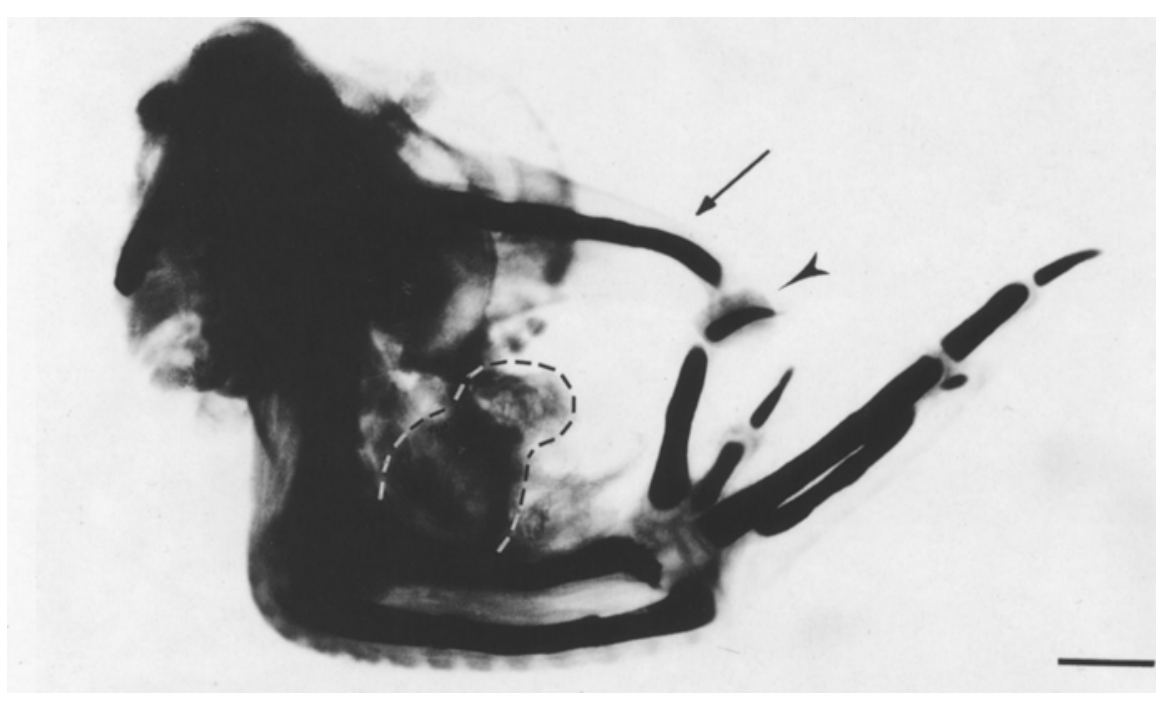

Fig. 3. Rod of supernumerary cartilage (arrow) proximal to graft (graft outlined by dashed line). An unidentifiable supernumerary digit developed distal to graft (arrowhead). Hensen's node from stage 5 quail embryo was grafted into anterior slit in wing of stage $21 \mathrm{chick}$ embryo. (Scale bar, $1 \mathrm{~mm}$ )
The majority of wings with grafts of frog kidney or lung developed normally. Normal wings usually developed $(85 \%, 17 / 20)$ following grafts of chick otic vesicles, but two wings $(10 \%, 2 / 20)$ had SN spurs of cartilage. In one case a long spur extended from the shoulder (Fig. 4a) and in the other case there was a projection of cartilage from the middle of the humerus (Fig. 4b).

No SN digits or rods of cartilage developed in wings with grafts of heteroinductor tissues; however, many of these wings developed abnormally (bent humerus, missing radius or ulna) and therefore were not included in the calculations (Table 4). There was only one wing with a SN structure: a tiny bump of cartilage developed in the middle of the radius of a wing containing a graft of mouse liver. The majority of the wings with grafts of mouse liver were normal $(88 \%, 15 / 17)$.

The wings that received grafts of optic cups developed with normal skeletons in $83 \%(15 / 18)$ of the cases (Table 4).

\section{Controls}

No SN digits or rods or nodules of cartilage developed from grafts of chick or quail Hensen's nodes to posterior slits in host chick wing buds. However, the majority of the wings (18/22) had very abnormal skeletal patterns, such as missing ulna, metacarpals, or digits; bent radius, ulna or digits; or missing ulna and digit 4 and a rod (sometimes with digit) at the elbow (Fig. 5). Of the 18 abnormal wings, 7 had a cartilage rod or nodule in the elbow and a missing or reduced ulna. These wings were not counted as having supernumeraries because if the cartilage structure in the elbow consisted of chick cells, one could not be sure that it was not part of the missing ulna, rather than a SN structure.

Control grafts of quail tissue anterior to Hensen's node (notochord) caused the wings to develop normally in two cases, and four wings were very abnormal (as described above). One otherwise normal wing had a tiny SN cartilage nodule beside the proximal end of the ulna, next to the graft. This wing was serially sectioned and the nodule consisted of chick cells. The results were similar following anterior grafts of tissue lateral to Hensen's node: 5 of the wings were normal, one wing was classified as "other non-SN" and 10 wings were very abnormal (as described above).

\section{Serial sections of operated wings}

Twelve wings with quail Hensen's node grafts were serially sectioned and examined by light microscopy. In ten cases, the $\mathrm{SN}$ structures contained only chick (host) 


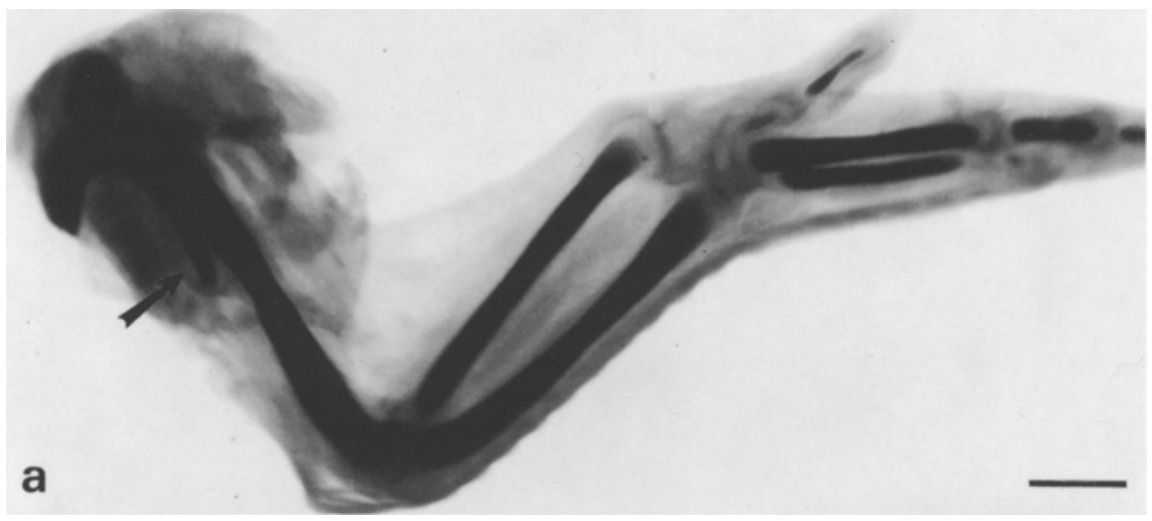

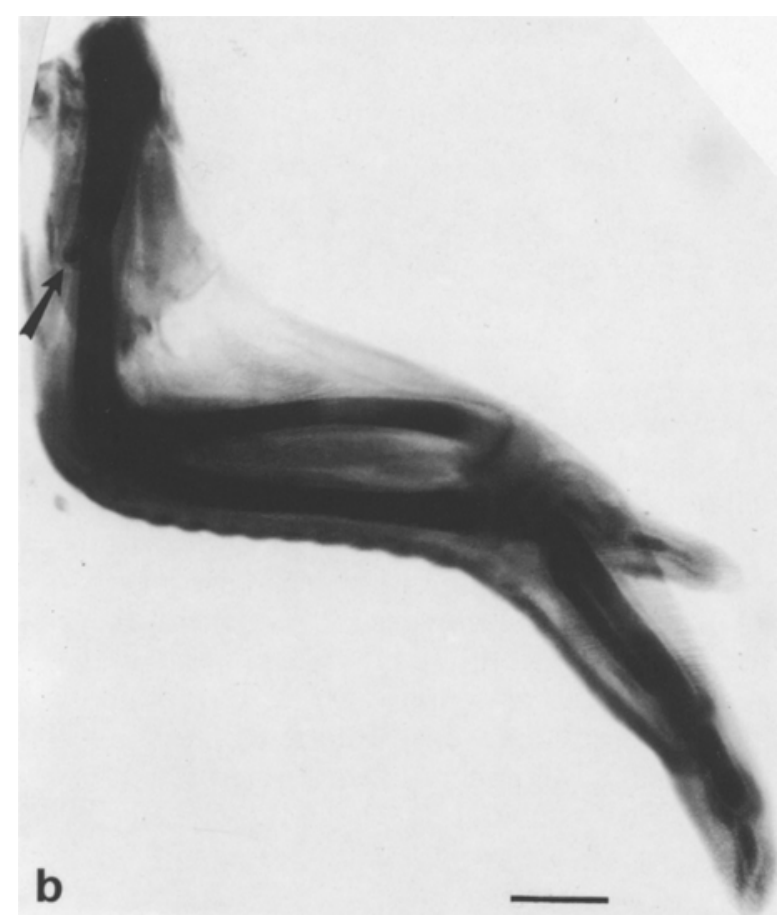

Fig. 4a, b. Whole mount preparations of two wings that received preaxial grafts of chick otic vesicles (Scale bar, $1 \mathrm{~mm}$ ). a Spur of supernumerary cartilage (arrow) extends from shoulder. Otic vesicle from stage 17 chick embryo was grafted into anterior slit in wing of stage 23 chick embryo. b Projection of supernumerary cartilage (arrow) from humerus. Otic vesicle from stage $17 \mathrm{chick}$ embryo was grafted into anterior slit in wing of stage 22 chick embryo

cells and the grafted tissue did not contribute to the supernumeraries (Fig. 6a, b, c). In two cases, however, 1-2 quail nephric tubules were found within the SN structure and could be traced back to their origin within the bulk of the graft. With the exception of some quail nephric tubules and neural tissue (which resembled neural tube), the graft cells remained cohesive and did not spread out within the host wing. Within the graft, various types of quail tissue were identified on the basis of their histological appearance, including loose mesenchyme ( $9 / 12$ wings), nephric tubules ( $7 / 12$ wings), and
Table 4. The formation of SN structures after grafts of inductivelyactive tissues into anterior slits in chick wing buds

$\begin{array}{ll}\begin{array}{l}\text { Tissue grafted } \\ \text { to anterior slit }\end{array} & \begin{array}{l}\text { Normal SN digits, "Other } \\ \text { wings } \begin{array}{l}\text { Other } \\ \text { nodules }\end{array}\end{array}\end{array}$

Limb-inducing tissues

\begin{tabular}{lclll}
$\begin{array}{l}\text { Frog lung } \\
\text { (male and female } \\
\text { Rana pipiens) }\end{array}$ & $\begin{array}{l}17 \\
(77 \%)\end{array}$ & - & $\begin{array}{l}5 \\
(23 \%)\end{array}$ & 2 \\
$\begin{array}{l}\text { Frog kidney } \\
\text { (male and female }\end{array}$ & 7 & - & 3 & 2 \\
$\begin{array}{l}\text { Rana pipiens) } \\
n=10\end{array}$ & $(70 \%)$ & & $(30 \%)$ & \\
$\begin{array}{l}\text { Chick otic vesicle } \\
\text { (stage } 17-19)\end{array}$ & 17 & 2 & 1 & - \\
\hline $\begin{array}{l}\text { (1) } \\
\text { (1) }\end{array}$ & $(85 \%)$ & $(10 \%)$ & $(5 \%)$ &
\end{tabular}
$n=20$

\section{Heteroinductors}

Rat kidney

(cortex) $(100 \%)$

male F455

$n=5$

Mouse liver

male C57

$n=17$

Rat submaxillary gland male F455 $n=5$

Rat urinary bladder male F455 $n=5$

Mouse submaxillary gland 4 male $\mathrm{C} 57 n=4$

Rat lung

female F 455

$n=5$

$\begin{array}{lll}15 & 1 & 1 \\ (88 \%) & (6 \%) & (6 \%)\end{array}$

1

$4 \quad-\quad 1 \quad 5$

Other tissue

Chick optic cup

(stage 13-17) $(80 \%)$

4

$n=18$

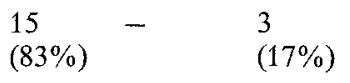




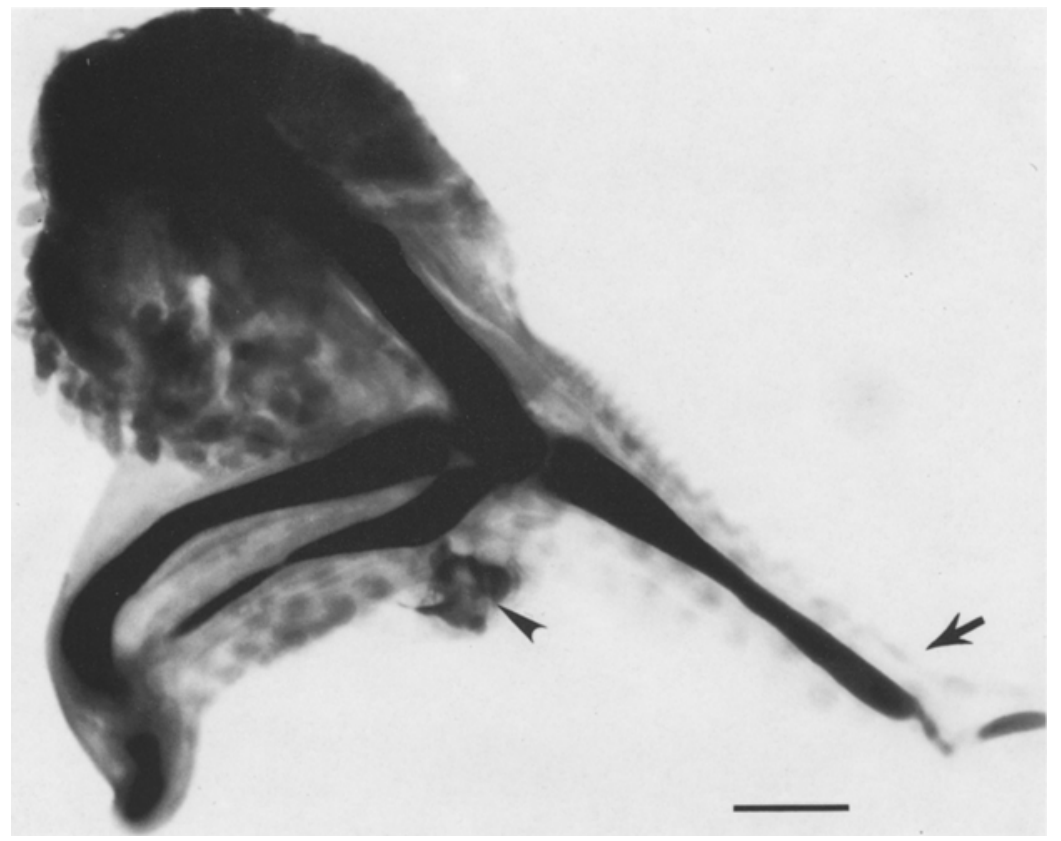

Fig. 5. Whole mount preparation of wing that received postaxial (into posterior slit) graft of Hensen's node from stage 5 quail embryo. Host was stage 21 chick embryo. Rod at elbow (arrow) consists of chick cells. Distal half of ulna is reduced; only one hypomorphic digit developed. Graft (arrowhead) is seen beside proximal end of ulna (Scale bar, $1 \mathrm{~mm}$ ) muscle, dense mesenchyme, and nerve (5/12 wings). Quail neural tube was found in all the sectioned wings and $92 \%(11 / 12)$ of the wings had quail notochord and cartilage within the graft (this cartilage was not counted as supernumerary in the whole mount preparations because it was clearly part of the graft itself).

Six of the serially sectioned wings described above had SN structures proximal to the graft, in addition to the SN digits distal to the graft. In each case the proximal SN structure consisted of chick (host) cells only.

Serial sections were made of five control wings in which a quail Hensen's node was grafted to a posterior slit. Two wings contained a rod sticking out of the elbow (Fig. 5) that consisted entirely of chick cells. In the other three wings there were chick cartilage nodules in the elbow or attached to the distal end of the humerus. In all five wings the ulna was partially or completely missing and in two wings digit 4 was also missing. The grafts all remained cohesive and in four wings they were located in the position normally occupied by the proximal end of the ulna; in the remaining wing the graft was beside digit 3 . These observations suggest that the rods and nodules in the elbow region were probably parts of the missing ulna that did not develop in their normal locations because of interference (mechanical?) by the graft. The grafts differentiated into all the tissues described above.

Serial sections were cut from four wings that had received frog organizer grafts to the anterior side. Although a bulge of soft tissue was found on the anterior side of three wings, the cells of the bulge could not be distinguished from the surrounding chick cells. One possibility is that the grafts had broken down and any necrotic tissue had been resolved by the time of fixation (6-7 days post-operatively). It is unlikely that the grafts fell out of the wings because each graft was present when the wings were examined $2-4 \mathrm{~h}$ after the operation (with grafts of quail tissue, this is a good indicator that the graft will not fall out subsequently).

Four wings in which adult frog kidney had been grafted into an anterior slit and which subsequently developed bent humeri were serially sectioned. In each wing the frog aephric tubules were apparent and the bend in the humerus was opposite the graft. This suggests that the graft may have interfered mechanically with the normal development of the humerus.

\section{Discussion}

Our results demonstrate that, like the ZPA, the avian Hensen's node can induce supernumerary digits to develop when it is grafted to an anterior position in a host chick wing bud. However, the polarizing activity of Hensen's node is somewhat attenuated compared to that of the ZPA. Approximately $60 \%$ of the wings in this experiment developed SN digits or rods of cartilage, whereas SN digits develop in $80-100 \%$ of the wings that have ZPA grafts to their anterior margins (Saunders and Gasseling 1968). In addition, recognizable supernumerary digit 4's (the most posterior digit) did not develop following grafts of Hensen's nodes; instead, the most common digital pattern was 2234 . Supernumerary digit 4's frequently develop after ZPA grafts (Saunders and Gasseling 1968).

These results are similar to those reported by Hornbruch and Wolpert (1986) for experiments in which chick Hensen's nodes were grafted directly under the apical ectodermal ridge (AER) on the anterior side of host chick wings. However, they did not report that any wings developed with SN structures far proximal to the graft. 

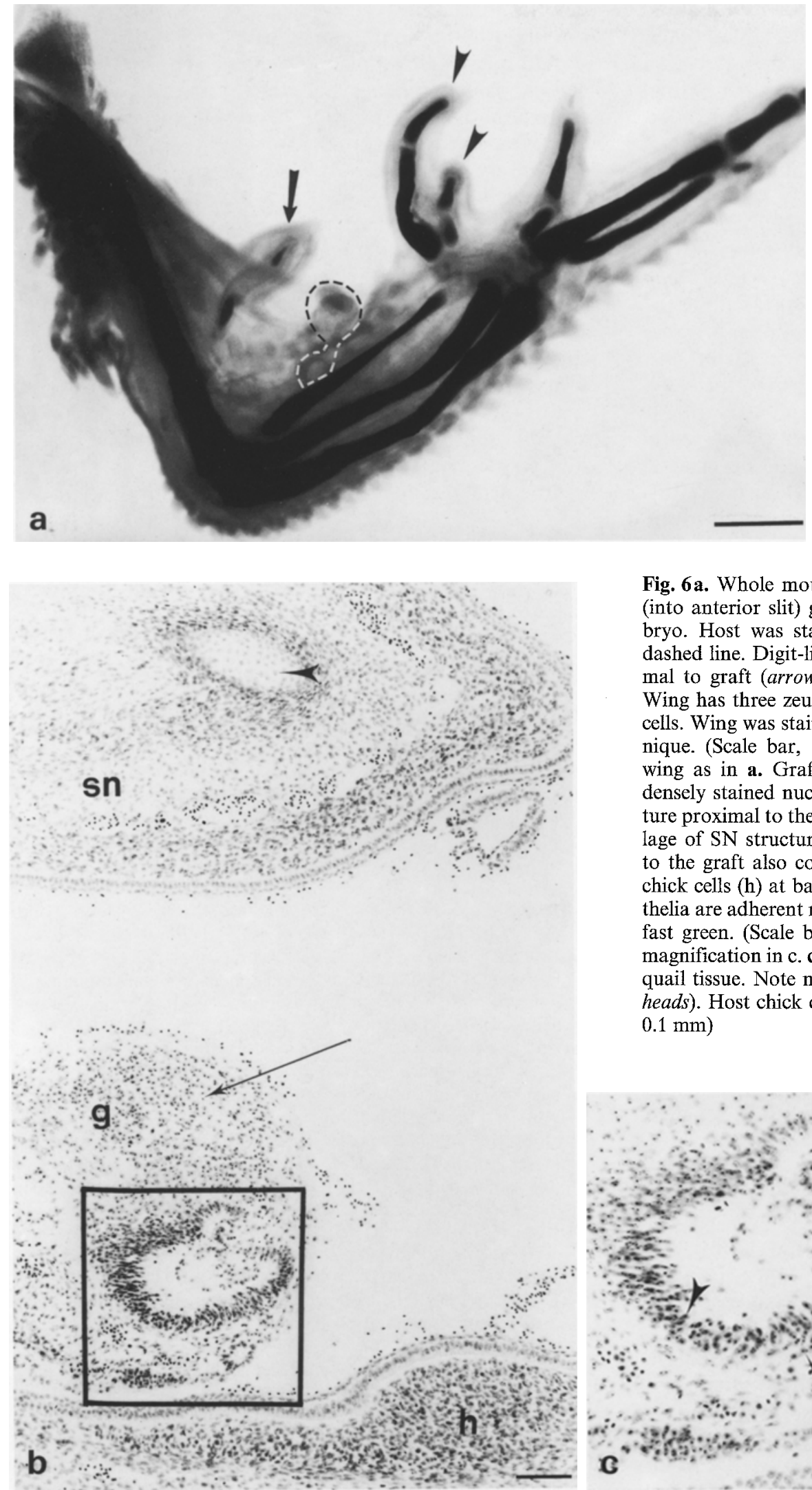

Fig. 6a. Whole mount preparation of wing that received preaxial (into anterior slit) graft of Hensen's node from stage 4 quail embryo. Host was stage $20+$ chick embryo. Graft is outlined by dashed line. Digit-like rod of supernumerary (SN) cartilage proximal to graft (arrow); two SN digits distal to graft (arrowheads). Wing has three zeugopodial elements; all consist entirely of chick cells. Wing was stained by combined Feulgen-Victoria blue B technique. (Scale bar, $1 \mathrm{~mm}$ ). b Sagittal section $(7 \mu \mathrm{m})$ of the same wing as in a. Graft ( $\mathrm{g}$ ) consists of quail cells, identified by the densely stained nuclear chromatin marker (arrow). The SN structure proximal to the graft (SN) consists entirely of chick cells (cartilage of SN structure marked by arrowhead). The SN digits distal to the graft also consist entirely of/chick cells (not shown). Host chick cells (h) at base of micrograph. Small dark cells outside epithelia are adherent red blood cells. Section was counterstained with fast green. (Scale bar, $0.1 \mathrm{~mm}$ ). Box outlines area seen at higher magnification in c. $\mathbf{c}$ Higher magnification view of region of grafted quail tissue. Note nuclear chromatin marker of quail cells (arrowheads). Host chick cells at base of micrograph (arrow). (Scale bar, $0.1 \mathrm{~mm}$ )

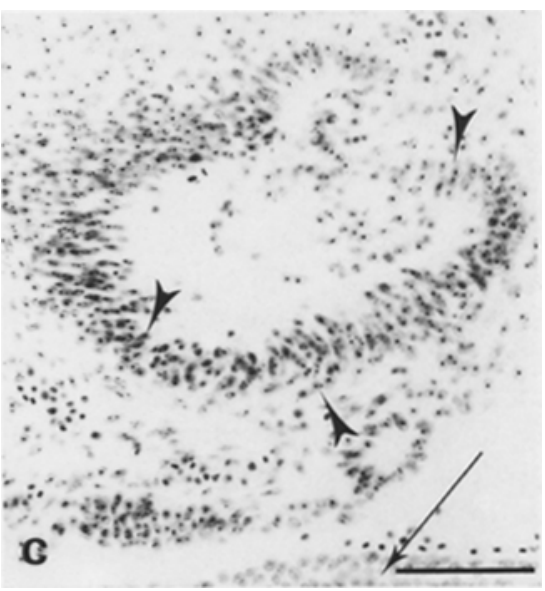


It is likely that the difference in the way we implanted the grafts (into a slit in the wing, rather than under the AER) is responsible for the difference in our results. In most of the wings that had SN structures proximal to the graft, the graft was implanted at the level of somites 15-16 and extended quite deeply into the wing. The graft might therefore influence the development of the proximal region of the wing.

In contrast to the results with avian Hensen's node grafts, supernumerary structures did not develop following grafts of the dorsal lip of the blastopore of Rana pipiens or Xenopus laevis. This result suggests that the host chick cells may not be able to respond to a signal from amphibian tissue; alternatively, a signal from amphibian tissue might be blocked or degraded in the chick wing or at $37^{\circ} \mathrm{C}$.

No supernumerary digits developed following grafts of tissues that can induce SN limbs in adult urodele amphibians or that act as heteroinductors in neural induction. Grafts of another inductive tissue, the optic cup, also failed to induce $\mathrm{SN}$ digits in the chick wing. However, many of these wings had abnormal skeletal patterns in which the humerus was bent or the radius or ulna was missing. It is most likely that the grafted heterospecific tissue was not properly integrated and disrupted normal development of the wing through a mechanical or blocking effect, so that normal cellular interactions and movements were disturbed. This would probably also explain the abnormal development of the control wings in which Hensen's node grafts were implanted in posterior slits, in the region of the developing elbow. Such gross abnormalities are less likely to occur following preaxial Hensen's node grafts because these are made into the region of the future anterior wing web (loose connective tissue), rather than into regions of future joints and long bones; furthermore, the grafted avian tissue is readily integrated into the host wing bud.

In a very small number of wings supernumerary spurs or nodules of cartilage developed following grafts of chick otic vesicles (10\% of the cases) and mouse liver ( $6 \%$ of the cases) to anterior slits in chick wings and following a graft of quail notochord to a posterior slit $(14 \%, 1 / 7)$. It is difficult to explain these results, particularly when the numbers are so small.

Tickle et al. (1985) demonstrated that SN digits develop in chick wings when beads that have been soaked in retinoic acid are grafted under the AER at the anterior margin of the wing. However, our results show that the wing bud is not so labile that it will respond to tissues that can induce SN limbs in adult urodele amphibians or tissues that act as heteroinductors in neural induction. The wing also does not respond to another inductivelyactive tissue, the chick optic cup. The induction of $\mathrm{SN}$ structures in the chick wing therefore differs from neural induction in early amphibian embryos, which can be triggered by many tissues and other non-specific stimuli (for a recent review, see Gurdon 1987). One cannot assume, however, that the mechanism of induction of SN structures is the same for the ZPA, retinoic acid, and Hensen's node, or that any of these phenomena repre- sent the mechanism of anteroposterior pattern formation in normal limb development.

Although we do not know the mechanism by which Hensen's node induces SN digits to form when it is grafted to the anterior side of a chick wing bud, the serial sections of operated wings clearly show that the graft rarely contributes to the SN structures. Thus the graft must provide a signal to which the host cells can respond, but we do not know whether this signal is a diffusible molecule(s) or a molecule(s) associated with the cell surface or the extracellular matrix.

The results of this study and the others described above show that polarizing activity is not limited to the ZPA in the wing bud. Nevertheless, many of the classic embryonic inductors, when implanted into the anterior part of the wing bud, do not elicit a polarizing response. When those tissues and agents that elicit a positive polarizing response are viewed as a group, there is thus far no obvious common factor that links them together.

Acknowledgements. The authors thank Jean Carlson and Beverly Shepard for their excellent technical assistance. Supported by NIH grant HD-17228 to BMC.

\section{References}

Balinsky BI (1925) Transplantation des Ohrbläschens bei Triton. Roux's Arch Dev Biol 105:718-731

Cameron J, Fallon JF (1977) Evidence for polarizing zone in the limb buds of Xenopus laevis. Dev Biol 55:320-330

Carlson BM (1967) Studies on the mechanism of implant-induced supernumerary limb formation in urodeles. I. The histology of supernumerary limb formation in the adult newt, Triturus viridescens. J Exp Zool 164:227-242

Carlson BM (1971) The distribution of supernumerary limb-inducing capacity in tissues of Rana pipiens. Oncology 25:365-371

Carlson BM, Simandl BK, Stocker KM, Connelly TG, Fallon JF (1986) A method for the combined gross skeletal staining and Feulgen staining of embryonic chick tissues. Stain Technol $61: 27-31$

Fallon JF, Crosby GM (1977) Polarizing zone activity in limb buds of amniotes. In: Ede DA, Hinchliffe JR, Balls M (eds). Vertebrate limb and somite morphogenesis. Cambridge University Press, Cambridge, pp 55-69

Gurdon JB (1987) Embryonic induction - molecular properties. Development 99:285-306

Hamburger V, Hamilton HL (1951) A series of normal stages in the development of the chick embryo. J Morphol 88:49-67

Hornbruch A, Wolpert L (1986) Positional signalling by Hensen's node when grafted to the chick limb bud. J Embryol Exp Morphol 94:257-265

Kim W-S, Stocum DL (1986a) Retinoic acid modifies positional memory in the anteroposterior axis of regenerating axolotl limbs. Dev Biol 114:170-179

Kim W-S, Stocum DL (1986b) Effects of retinoic acid on regenerating and double half limbs of axolotls: Histological studies. Roux's Arch Dev Biol 195:243-251

LeDouarin N (1973) A biological cell labeling technique and its use in experimental embryology. Dev Biol 30:217-222

MacCabe AB, Gasseling MT, Saunders JW Jr (1973) Spatiotemporal distribution of mechanisms that control outgrowth and anteroposterior polarization of the limb bud in the chick embryo. Mech Ageing Dev 2:1-12

Maden M (1982) Vitamin A and pattern formation in the regenerating limb. Nature 295:672-675 
Maden M (1985) Retinoids and the control of pattern in limb development and regeneration. Trends Genet 1:103-107

Maden M, Ong DE, Summerbell D, Chytil F (1988) Spatial distribution of cellular protein binding to retinoic acid in the chick limb bud. Nature 335:733-735

Nieuwkoop PD, Faber $\mathbf{J}$ (1956) Normal table of Xenopus laevis (Daudin). North Holland, Amsterdam

Saunders JW Jr (1977) The experimental analysis of chick limb bud development. In: Ede DA, Hinchliffe JR, Balls M (eds). Vertebrate limb and somite morphogenesis. Cambridge University Press, Cambridge, pp 1-24

Saunders JW Jr, Gasseling MT (1968) Ectodermal-mesenchymal interactions in the origin of limb symmetry. In: Fleischmajer $\mathrm{R}$, Billingham RE (eds) Epithelial-mesenchymal interactions. Williams and Wilkins, Baltimore, pp 78-97

Saunders JW Jr, Gasseling MT (1983) New insights into the prob- lem of pattern regulation in the limb bud of the chick embryo. In: Fallon JF, Caplan AI (eds) Limb development and regeneration, Part A. AR Liss, New York, pp 67-76

Saxen L, Toivonen S (1962) Primary embryonic induction. Logos Press, London

Shumway W (1940) Stages in the normal development of Rana pipiens. I. External form. Anat Rec 78:139-147

Thaller C, Eichele G (1987) Identification and spatial distribution of retinoids in the developing chick limb bud. Nature 327:625628

Tickle C, Lee J, Eichele G (1985) Quantitative analysis of the effect of all-trans-retinoic acid on the pattern of chick wing development. Dev Biol 109:82-95

Tickle C, Summerbell D, Wolpert L (1975) Positional signalling and specification of digits in chick limb morphogenesis. Nature 254:199-202 